\title{
New Issues and Opportunities in Service Design Research
}

\author{
Rohit Verma \\ David Eccles School of Business, University of Utah, Salt Lake City, UT 84112, USA; Corresponding author. \\ Tel.: +1-801-585-5263, fax: +1-801-581-7214, E-mail addresses: rohit.verma@business.utah.edu \\ James Fitzsimmons \\ McCombs School of Business, University of Texas at Austin, Austin TX 78712-1174, USA; Tel.: +1-512-471- \\ 9453, E-mail addresses: jfitz@mail.utexas.edu \\ Janelle Heineke
}

School of Management, Boston University, 595 Commonwealth Avenue Boston, MA 02215, USA; Tel.: +1617-353-2919, E-mail addresses: jheineke@bu.edu

Mark Davis

Bentley College, 175 Forest Street, Waltham, MA 02452-4705, USA; Tel.: +1-781-891-2739; fax: +1-781891-2896, E-mail addresses: mdavis@bentley.edu

There is no such thing as a service industry. There are only industries whose service components are greater or less than those of other industries. Everybody is in service (Levitt, 1972).

There is ample evidence that a well-designed service system is a representation of the "quality of life" in many societies. It is also well known that the service sector now constitutes more than 70\% of the GDP in many developed economies. For example, according to the 1999 Statistical Yearbook (United Nations, 1999) service sector employment is greater then $80 \%$ in United States, and greater then $70 \%$ in Canada, Japan, France, Israel, and Australia. Due to rapid developments in information technology, globalization, changing customer needs/preferences, and the changes in relative wealth between the developed and newly developing economies, the effective design of service systems will become even more important in the coming years. Some researchers argue that several developed nations have moved beyond the service economy to the experience economy. In these cases, the ability to design effective systems for creating desired customer experiences will increasingly become the competitive advantage (Pine II and Gilmore, 1998).

In an era of intense high-speed competition, offering to the marketplace a sustainable and profitable value proposition that effectively leverages a firm's financial, human, and operational resources is critical to both established and emerging businesses. To complicate matters further, in emerging industries such as e-services, customers often do not know what 
they want or need, consequently limiting a the company's ability to engineer market-winning product-service solutions.

While companies develop their own strategies to compete effectively in the "new" new economy, this competitive environment offers many opportunities to scholars interest in studying services. For example, should an enterprise merely try to adapt to the e-services marketplace? Should it keep juggling with the endless list of alternative service offerings? Or should it strive to shape the future of the business environment within which it operates by offering innovative product-service bundles?

Thanks to the tireless efforts of countless volunteers from Service Operations Management Association (SOMA, a.k.a. Service Management Interest Group (SMIG) http://soma.byu.edu), service design has evolved to become a live, fruitful, active and mainstream research topic. Also thanks to the leadership of DSI, INFORMS and POMS, many invited sessions on topics related to service design have been organized during their national and international conferences. Many journal editors, including those of Decision Sciences, International Journal of Service Industry Management, Journal of Operations Management, Journal of Service Research, Manufacturing \& Service Operations Management, and Production and Operations Management have also encouraged manuscripts on services and are sponsoring upcoming special issues.

Following the success of a series of invited panel sessions organized during the 2000 annual DSI meeting in Orlando, FL, Jack Meredith, editor-in-chief, Journal of Operations Management, approved the development of an invited issue on "New Issues and Opportunities in Service Design Research." More than 20 participants from the DSI 2000 "service design" panels collectively developed five manuscripts that after undergoing a rigorous review process were accepted for publication in this special issue of the Journal of Operations Management. Each team selected its own "lead author" and followed a Delphi-type procedure to develop the manuscripts. The authors submitted their manuscripts for initial review during JanuaryFebruary 2001. Each manuscript was assigned to a lead editor (one of the four guest editors) who reviewed the paper along with two or three other reviewers, using a standard blind review process. The initial review process was completed in May-June 2001. Revised manuscripts were received from July to October 2001 and the review process was completed a week prior to 2001 DSI meeting.

Each of the members of the five author teams deserve special recognition for meeting tight deadlines and for their willingness to work closely with their colleagues (almost entirely electronically) in the preparation of these manuscripts. Although many of the authors for this special issue are well-recognized members of the service management community, many worked together on this project for the first time. The author teams include both "senior" and relatively new service management researchers. 
In "The Service Concept: The Missing Link in Service Design Research." Susan MeyerGoldstein, Robert Johnston, Jo Ann Duffy and Jay Rao suggest that the Service Concept plays a key role in service design and development. They define the Service Concept and describe how it can enhance service design planning and service recovery design processes. Employing the Service Concept as an important driver of service design decisions raises a number of interesting questions for research that are presented here.

The second paper, "New Service Development (NSD): Areas for Exploitation and Exploration," co-authored by Larry Menor, Mohan Tatikonda and Scott Sampson, argues that the management of NSD has become an important competitive issue in many service industries. However, NSD still remains among the least studied and understood topics in the service management literature. They suggest that, until recently, the generally accepted principle behind NSD was that "new services happen" rather than arise through formal development processes. Relying upon the general distinction between exploitation and exploration in organizational learning, this paper describes areas in NSD research that deserve further attention and refinement (i.e. exploitation) and identifies areas requiring discovery or diverse study (i.e. exploration).

Lori Cook, David Bowen, Richard Chase, Sriram Dasu, Douglas Stewart, and David Tansik in the paper titled "Human Issues in Service Design" discuss how the basic behavioral principles underlying human interactions can be translated directly into service design. Human issues from the customer and service provider vantage points are illustrated and challenges to researchers for exploring these perspectives are presented.

The fourth paper, titled "e-Services: Operating Strategy, A Case Study and A Method for Analyzing Operational Benefits," co-authored by Ken Boyer, Roger Hallowell and Aleda Roth, discusses the role of service design in interactive delivery channels such as the Internet. This paper examines e-services using three approaches to provide guidance on how to "fly" rather than "flop." The authors present a model for e-service customer retention, include a case study, and offer a profiling technique for analyzing the benefits and challenges of e-services for particular industries.

Finally, in "Research Opportunities in Service Process Design," Art Hill, David Collier, Craig Froehle, John Goodale, Richard Metters and Rohit Verma, present an overview of the new research opportunities related to service operations design topics such as the design of retail and e-tail service processes, design of service processes involving waiting lines, service design for manufacturing, and re-engineering service processes. For each topic, the paper presents an overview of the topic, the relevant frameworks, and a discussion of the research opportunities. The integrating theme of the paper is that research on service process design is inherently multi-disciplinary and requires a variety of research methodologies.

These papers all provide insights both for the scholarly study of services and for the practice of service management. The breadth of these papers demonstrates not only how much 
service operations scholars have learned about NSD, but also how much there is still to be learned about not only service design but services in general. The changes that we are witnessing today with respect to the introduction of new types of services will continue into the foreseeable future, and most likely at an even faster rate than we are now experiencing. It is, therefore, important for both academics and practitioners alike to more fully understand the NSD process and its impact on the success of a company. We hope that this special issue of the Journal of Operations Management represents an initial step towards that understanding.

Welcome to the age of "value-added" services economy!

\section{References}

Levitt, T., 1972. Production-line approach to service. Harvard Business Review 50 (5), 41-52.

Pine II, B.J., Gilmore, J.H., 1998. Welcome to the experience economy. Harvard Business Review 7, 97-105. 